\title{
INHERITED GENETIC SUSCEPTIBILITY TO BREAST CANCER IN PAKISTAN
}

\author{
Noor Muhammad, Ramsha Nawaz, Faiz A. Khan, Humaira Naeemi, Muhammad U. Rashid \\ Department of Basic Sciences Research, Shaukat Khanum Memorial Cancer Hospital and Research Centre, Lahore, \\ Pakistan
}

Received: 12 June 2017 / Accepted: 25 June 2017

\begin{abstract}
Breast cancer is a heterogeneous disease. Several genetic, environmental and lifestyle factors are involved in the aetiology of this disease. Genetic risk factors include alterations (mutations) in genes conferring risks to develop breast cancer. Depending on the associated lifetime risks of this malignancy, these genes are categorised into high-, moderate- and low-risk genes. Women carrying mutations in these genes are at an increased risk to develop breast cancer, ovarian cancer and several other malignancies. Breast carcinoma is the most reported malignancy in Pakistani females. Pakistan is a developing country with most of its population living in rural areas; hence, optimal healthcare facilities are inadequate for the early diagnosis and prevention of this disease. Hence, identification of individuals carrying mutations is clinically relevant as different strategies are available for the early detection, risk reduction and better management of this malignancy. This review summarises the findings of the major studies conducted in Pakistan to investigate the contribution of breast cancer predisposing genes. Furthermore, implications of the current studies and future research potentials are discussed.
\end{abstract}

Key words: Breast cancer gene 1/2, breast cancer, checkpoint kinase 2, genetic susceptibility, Pakistan, RAD51C, tumour Protein p53, Vitamin D receptor

\section{Introduction}

Breast cancer is the most frequent invasive malignancy diagnosed among women worldwide. It ranks first among both the industrialised and developing world. ${ }^{[1]}$ The annual incidence rate of $\sim 1.67$ million breast cancers was reported in the year 2012. ${ }^{[2]}$ It is also the major cause of mortality among women worldwide, responsible for 0.5 million deaths in the year 2012. ${ }^{[2]}$ Within Asia, 0.65 million new breast cancer cases were diagnosed and 0.23 million died due to this illness in the year 2012. ${ }^{[2]}$ Breast cancer is the leading public health issue in Pakistani women. It is the commonly reported cancer among Pakistani females. 34,038 new breast cancer cases and 16,232 deaths are reported each year. ${ }^{[3]}$ Pakistan has a high incidence of this disease in Asia. Women are generally diagnosed at an early age and with an advanced disease. ${ }^{[4]}$ Hence, it is crucial to identify risk factors of this malignancy and further introduce the

Correspondence: Dr. Muhammad U. Rashid, Department of

Basic Sciences Research, Shaukat Khanum Memorial

Cancer Hospital and Research Centre.

Email: usmanr@skm.org.pk breast cancer awareness programs and early detection strategies.

Breast cancer is a complex disease. A strong interaction of genetic and non-genetic risk factors is linked with this disease. A large case-control study from Pakistan comprising 463 early-onset or familial breast cancer cases and 1012 healthy individuals revealed that majority were reported with early age at menarche $<13$ years $(58.8 \%$ vs. $53.1 \%, P=0.04)$, a fewer number of full-term pregnancies $<3(76.5 \%$ vs. $63.5 \%, P<0.0001)$, a later age at full-term pregnancy $>20$ years $(57.2 \%$ vs. $48.2 \%, P=0.02)$, shorter duration of breastfeeding of $<23$ months ( $20.5 \%$ vs. $12.3 \%$, $P<0.0001$ ), post-menopausal (23.1\% vs. cancer. Sporadic breast cancer develops in an individual without any family history of this disease. Such cancers are unilateral and present at later ages $17.6 \%, P=0.02)$ and belonged to Pathan or Kashmiri ethnicities ( $16.7 \%$ vs. $11 \%, P=0.03)$ compared to the control population. ${ }^{[5]}$

There are three different types of breast cancer including sporadic, familial and hereditary breast cancer. Sporadic breast cancer develops in an individual without any family 
history of this disease. Such cancers are unilateral and present at later ages. ${ }^{[6]}$ Most breast cancers are sporadic and arise due to acquired genetic changes, environmental factors and interactions between these factors. Familial breast cancer occurs in an individual who reports at least one breast cancer among close relatives. This constitutes between $15 \%$ and $20 \%$ of all breast cancers. This form of breast cancer develops due to inherited changes in moderate- and low-penetrance genes. ${ }^{[7,8]}$ Plausibly, a polygenic mechanism of numerous alleles having an additive or multiplicative effect ${ }^{[9]}$ and environmental factors contribute to disease development. Hereditary breast and/or ovarian cancer (HBOC) occur in an individual who reports a personal and/or family history of at least one breast and ovarian cancer. There are parameters suggestive of the hereditary form of the disease [Table 1]. Approximately $5-10 \%$ of all breast cancers are hereditary and occur due to inherited mutations in major breast cancer-associated genes. ${ }^{[10]}$

The genes linked with breast cancer are divided into three different categories based on their lifetime risk of developing breast cancer. It includes highpenetrance genes (breast cancer gene 1 [BRCA1], $B R C A 2$, tumour protein p53 [TP53] and phosphatase and tensin homolog), moderate-penetrance genes (cell cycle checkpoint kinase 2 [CHEK2], PALB2, ATM, BRIP1, RAD51C and RAD51D) and low-penetrance breast cancer loci (single nucleotide polymorphisms [SNPs] in Vitamin D receptor [VDR], mitogen-activated protein kinase kinase kinase 1, fibroblast growth factor receptor 2, lymphocyte-specific protein 1, TNRC19, H19 and caspase 8). ${ }^{[7]}$ Mutations in high-penetrance genes are linked with a high risk (relative risk $>5$ ). Moderatepenetrance genes confer a moderate risk (relative risk 1.5-5). Low-penetrance genes are associated with low risk (relative risk up to 1.5 ). ${ }^{[7]}$

Clinical significance of breast cancer predisposing genes and associated mutations relies on its prevalence in a specific population. In this review, we summarise the findings from major studies conducted in the Pakistani population explaining the contribution of breast cancer susceptibility genes to Pakistani breast cancer patients. We also discuss the implications of current studies and potential for future research.

\section{High-penetrance Genes BRCA1 and BRCA2}

BRCA1 (OMIM 113705) was mapped on chromosome $17 \mathrm{q} 21$ in the year 1990 by linkage analysis of early-onset breast cancer families. ${ }^{[1]}$ This gene comprises $110 \mathrm{~kb}$ of DNA sequence and comprises 24 exons. It encodes 208 kilo Dalton $(\mathrm{kDa})$ proteins of 1863 amino acid residues. $B R C A 1$ has three domains: A RING-finger domain at the 5 ' end, a classic nuclear localisation sequence in the centre and a BRCA1 carboxyl-terminal domain at the 3' end of the protein. ${ }^{[12,13]}$

BRCA2 (OMIM 600185) was mapped on the long arm of chromosome 13 (q12-13) in the year 1995..$^{[14]}$ This gene includes $70 \mathrm{~kb}$ of genomic DNA and comprises 27 exons. It encodes a $384 \mathrm{kDa}$ protein of 3418 amino acid residues. BRCA2 contains eight copies of 30-80 amino acid repeats (BCR repeats) in the centre of the protein. ${ }^{[15]}$

\section{Table 1: Parameters suggestive of hereditary breast and/or ovarian cancer}

\begin{tabular}{l}
\hline Female breast cancer at a young age \\
\hline Bilateral breast cancer \\
\hline More than 2 first-degree relatives affected with breast cancer $<50$ years of age \\
\hline The same individual affected with breast and ovarian cancer \\
\hline Several individuals affected with breast cancer at a young age and ovarian cancer at any age \\
\hline Male breast cancer \\
\hline Presence of other BRCA1/2-associated cancers (e.g., prostate, pancreatic, gallbladder, bile duct and melanoma) \\
\hline Autosomal-dominant pattern of inheritance \\
\hline Few ethnic groups (e.g., Ashkenazi Jewish, Polish and Icelanders) in association with a personal and/or familial history of \\
breast and/or ovarian cancer \\
\hline BRCA1: Breast cancer gene 1, BRCA2: Breast cancer gene 2
\end{tabular}


Both BRCA1 and BRCA2 (BRCA1/2) are tumour suppressor genes. ${ }^{[16,17]}$ Both genes are involved in the maintenance of genomic stability, repair of damaged DNA and control of cell cycle checkpoints during the process of cell division. ${ }^{[18]}$ BRCA1/2 mutations cause early-onset breast cancer, familial breast cancer and HBOC. Women harbouring mutations in BRCA1/2 have $>50 \%$ risk of developing breast cancer and $39-44 \%$ or $11-18 \%$ risk of developing ovarian cancer by the age of 70, respectively. ${ }^{[19-21]}$ Among male BRCA1/2 mutation carriers, there are $1.2 \%$ and $6.8 \%$ risk of developing breast cancer by the age of 70 , respectively. ${ }^{[22]}$

The frequencies and the spectrum of BRCA1/2 mutations vary among different ethnic populations and with geographic distributions. Most Asian studies showed that the $B R C A 2$ mutations are more common than the $B R C A 1$ mutations. ${ }^{[23]}$ Conversely, BRCA1 mutations are more prevalent in Pakistan. ${ }^{[24-28]}$

Only one comprehensive study has been conducted in Pakistan to assess the contribution of $B R C A 1 / 2$ small-range mutations in young and familial breast cancer patients. $^{[24]} 30$ disease-causative mutations in BRCA1 $(n=23)$ or $B R C A 2(n=7)$ were detected in 176 families $(17.0 \%)$. BRCA1/2 mutations were reported with the frequency of $23.8 \%$ (10/42) for families with at least two breast cancer cases and $11.9 \%(10 / 84)$ for young breast cancer cases diagnosed $\leq 30$ years. The highest mutation frequency of $50.0 \%(7 / 14)$ was reported in HBOC families. Four BRCA1 mutations in exon 2, exon 15 and exon 24 were identified in multiple unrelated families, accounting for 52\% (12/23) of all BRCA1 mutations. Haplotype analysis showed identical allelic patterns for three mutations suggesting founder effects. ${ }^{[24]}$ This study highlighted the substantial contribution of $B R C A 1 / 2$ mutations in Pakistan.

Two other studies have also assessed the frequency of $B R C A 1 / 2$ small-range mutations in unselected breast cancer cases from Pakistan. In the first study by Liede et al., 341 cases were analysed for BRCA1 (exon 2, exons 11-12, exon 15 and exon 20) and BRCA2 (exons 10-11 and exon 22) and reported that $6.7 \%$ (23/341) of patients harboured the deleterious mutations in both genes. ${ }^{[25]}$ However, screening of unselected patients and limited analysis of coding regions of $B R C A 1 / 2$ genes may have compromised the overall strength of this study. In another small study, BRCA1/2 mutation screening was performed among 77 cases from the Southwestern region of Pakistan (Balochistan province) and four mutations were detected $(5.2 \%, 4 / 77){ }^{[26]}$

Large deletions or duplications in BRCA1/2 (large genomic rearrangements [LGRs]) have recently been identified in breast cancer patients who did not carry small-range mutations in these genes. Since small-range mutations in BRCA1/2 contributed to only $17 \%$ of those breast cancer patients diagnosed at a young age or reported a family history of breast/ovarian cancer in Pakistan, it became necessary to screen these families for BRCA1/2 LGRs. A cohort of 120 Pakistani breast cancer patients diagnosed $\leq 30$ or with the family history of breast/ovarian cancer were screened for $B R C A 1 / 2$ LGRs. ${ }^{[27]}$ Three different $B R C A 1$ LGRs were identified in four families $(3.3 \%$, $4 / 120)$. Screening of another group of 445 patients for three LGRs using deletion-specific polymerase chain reactionbased assay detected ten more deletions with the frequency of $2.2 \%$ (10/445). Overall, two BRCA1 LGRs (deletion of exons 1-2 and deletion of exons 21-24) were recurrent, accounting for $92.8 \%(13 / 14)$ of all identified LGRs. BRCA2 LGRs were absent in Pakistani population. ${ }^{[27]}$

The pathological features of $B R C A 1 / 2$-associated tumours differ from those of non-carriers. This was determined in a study considering Pakistani triple-negative breast cancer (TNBC) patients. ${ }^{[28]}$ TNBC patients lack the expression of progesterone receptor, oestrogen receptor and human epidermal growth factor receptor 2 . This study included 523 breast cancer patients, of which 192 were TNBC and 331 were non-TNBC. BRCA1 mutations were significantly associated with TNBC phenotype (37\%) as compared to non-TNBC (10\%). ${ }^{[28]}$ Previously, a Pakistani woman with metaplastic breast carcinoma was reported to harbour BRCA1 185delAG mutation and further showed TNBC features. ${ }^{[29]}$

It has been reported that $B R C A 1 / 2$ mutation carrier status affects the ratio of female-to-male births, and the mutant allele is non-randomly transmitted to female offspring. ${ }^{[30]}$ However, sex ratio of offspring of $B R C A 1 / 2$ carriers was not different from the non-carriers in the Pakistani population. ${ }^{[31]}$ Males identified with $B R C A 1 / 2$ mutations have an increased risk of multiple cancers. ${ }^{[22]}$ Similarly, 
we noted a male renal cancer patient from Pakistan, carrying BRCA1 2080insA deleterious germline mutation with familial aggregation of 25 cancers including breast carcinoma. ${ }^{[32]}$

In humans, almost all individuals harbouring $B R C A 1 / 2$ mutation were reported heterozygous. Evidence from animal model studies showed that homozygous BRCA1/2 mutations are embryonic lethal. ${ }^{[33]}$ Hence, human foetuses with homozygous BRCA1/2 mutations may be more predisposed to spontaneous abortions. Therefore, it is possible that $B R C A 1 / 2$ mutation carriers with a history of parental consanguinity may have more rates of miscarriages. To test this hypothesis, Rashid et al. investigated the association of miscarriages and BRCA1/2 carrier status in Pakistani patients who were the progeny of consanguineous parents. ${ }^{[34]}$ The study comprised of 128 individuals who had at least one pregnancy, including 29 BRCA1/2 carriers and 99 non-carriers. In agreement with previous reports, no association between miscarriage and parental consanguinity was observed. ${ }^{[34]}$

To optimise cancer risk management, it is crucial to identify BRCA1/2 mutation carriers. After the comprehensive assessment of personal and family history, genetic testing is offered to high-risk patients. First-degree relatives of the patient harbouring the mutation are invited for predictive testing. However, interpretation of results becomes challenging among families with consanguineous marriages. This aspect is recently highlighted in a Pakistani HBOC family with four consanguineous marriages. In this family, BRCA1 c.1961 dupA mutation was detected in the index breast cancer patient. As per conventional guidelines, her relatives at risk of developing breast/ovarian cancer were offered for the family-specific mutation testing. One of the index patient's sisters with ovarian cancer did not carry the family-specific mutation. Testing was also offered to her daughters as their parents were first cousins. Mutation was detected in one daughter, showing that she harboured this mutation from her father who was unaffected i.e., without any malignancy. ${ }^{[35]}$ The study highlighted the significance of family-specific mutation testing to offspring who were the progeny of consanguineous parents from Pakistani and other populations. ${ }^{[35]}$

\section{TP53}

TP53 (OMIM 191170) is another high-penetrance breast cancer susceptibility gene and localised on chromosome $17 \mathrm{p} 13.1$. It covers $25.8 \mathrm{~kb}$ of gDNA and has 11 exons. TP53 encodes a $43.7 \mathrm{kDa}$ protein of 393 amino acid residues. It has six different structural or functional domains. ${ }^{[36]}$ p53 plays a key role in transcription, repair of damaged DNA, stability of the genome, control of cell cycle and apoptosis. ${ }^{[37]}$ TP53 mutations cause Li-Fraumeni syndrome (LS) (OMIM 151623). LS is an autosomal dominant disorder ${ }^{[38]}$ of several malignancies including breast cancer at the young age, soft tissue sarcoma, lung cancer, leukaemia, brain and adrenocortical tumours. ${ }^{[39]}$ Women harbouring TP53 germline mutations are prone to high lifetime risk of developing cancers (nearly 100\%). This is due to high incidence rates of breast cancer in women while the risks are lower for men $(73 \%) .^{[40]}$

A TP53 codon 72 SNP is considered as a potential breast cancer risk since the substitution occurs within the proline-rich domain of p53 and may affect the protein structure. However, the results from various populations are inconclusive. ${ }^{[41]}$ The frequency of proline allele in TP53 codon 72 is more reported in 150 sporadic Pakistani patients. ${ }^{[42]}$ Among young breast cancer patients, the frequency of TP53 mutations is $<5 \%$ for Caucasians, ${ }^{[43-45]}$ while limited data are available for Asian populations. In 2012, Rashid et al. analysed the complete TP53 gene in 105 Pakistani BRCA1/2-negative early-onset breast cancer patients diagnosed $<40$ years of age and not fulfilling the criteria of LS. One frameshift mutation (c.499_500delCA) was detected with the frequency of $1 \%(1 / 105) .{ }^{[46]}$ These findings showed a limited contribution of TP53 mutations to young Pakistani breast cancer patients. ${ }^{[46]}$

\section{Moderate-penetrance Genes}

Several moderate-penetrance genes are also reported to contribute to breast cancer risk. Of these genes, few genes have been investigated in the Pakistani population. ${ }^{[47,48]}$

\section{CHEK2}

CHEK2 (OMIM 604373) is mapped on chromosomal position 22q12.1. It covers $54.7 \mathrm{~kb}$ of genomic DNA and has 15 exons. It encodes a $60.9 \mathrm{kDa}$ protein of 543 amino acids residues. CHEK2 is a $\mathrm{G} 2$ checkpoint serine/threonine 
kinase. In the event of breakage in DNA double strand, CHEK2 acts as a tumour suppressor protein. ${ }^{[49]}$ CHEK2 has three functional domains: A SQ/TQ cluster domain at $\mathrm{N}$-terminus, forkhead-associated domain in the centre and a serine/threonine kinase domain at C-terminus. ${ }^{[50]}$

CHEK2 mutations confer a moderate risk for breast and multiple other cancers. ${ }^{[51]}$ Among familial cases, different mutations in this gene have been detected with varied frequencies and specific to geographical location and ethnicity. ${ }^{[52]}$ Women harbouring pathogenic CHEK2 mutations and with a family history of breast cancer face a lifetime risk of breast cancer development of over $25 \%{ }^{[53]}$ Most studies were restricted to examine the prevalence of common c. 1100 delC mutation ${ }^{[54,55]}$ since it had been linked with the risk of breast cancer among Northern/Western European populations. ${ }^{[56,57]}$ This mutation is absent in Asian populations, ${ }^{[55,58]}$ including Pakistan ${ }^{[47]}$ and the neighbouring regions of India ${ }^{[59]}$ and Iran. ${ }^{[60]}$

In 2013, Rashid et al. conducted the first comprehensive study from Pakistan and screened CHEK2 gene in 145 young and familial breast/ovarian cancer patients who were tested negative for $B R C A 1 / 2$ mutations. Two missense mutations (p.P92R and p.R406C) were identified with a frequency of $1.4 \%(2 / 145) .{ }^{[47]}$ These mutations were absent in 229 early-onset/familial patients not harbouring BRCA1/2 mutations. Other two missense mutations (p.H371Y and p.D438Y) were reported in another small study including 40 unselected breast cancer patients from Balochistan. ${ }^{[61]}$ No protein truncating CHEK2 mutations were detected in both studies. These findings suggested that the CHEK2 mutations may not confer to breast/ ovarian cancer susceptibility in Pakistan.

\section{RAD51C}

$R A D 51 C$ (OMIM 602774) is another moderate-penetrance breast cancer susceptibility gene at $17 q 22$. This gene covers $43 \mathrm{~kb}$ of genomic DNA and has 9 exons. It encodes a $42.2 \mathrm{kDa}$ protein of 376 amino acids residues. It is crucial in maintaining the stability of the genome through homologous recombination and DNA damage repair.

Homozygous RAD51C mutations were reported in one Pakistani consanguineous family with characteristics of Fanconi anaemia (FA). ${ }^{[62]}$ Later on, heterozygous
RAD51C mutations were observed in HBOC families. ${ }^{[63]}$ Overall, pathogenic mutations in $R A D 51 C$ were found in patients with a family history of $\mathrm{HBOC}$, suggesting its association with ovarian cancer. ${ }^{[64]}$ A variable $R A D 51 C$ mutation frequency ranging from 0.6 to $2.9 \%$ is reported in HBOC families from Caucasian population. ${ }^{[65,66]} R A D 51 C$ mutations were not found in HBOC families from China. ${ }^{[67]}$ A large RAD51C deletion (exons 6-9) was reported in 1\% $(1 / 100)$ of Japanese HBOC families. ${ }^{[68]}$ So far, only one such study is conducted in Pakistan. Analysis of RAD51C in 348 Pakistani breast/ovarian cancer patients, who were negative for $B R C A 1 / 2$ mutations, showed three novel pathogenic mutations with a frequency of $0.9 \%(3 / 348) .{ }^{[48]}$ The RAD51C mutations were more frequent in young ovarian cancer patients $(4.5 \%, 1 / 22)$ than the mutations in familial breast cancer patients $(0.8 \%, 1 / 119)$. Overall, the findings suggested that $R A D 51 C$ does not contribute to breast and ovarian cancer in Pakistani women. ${ }^{[48]}$

\section{FA complementation group $\mathrm{M}(\boldsymbol{F A N C M})$}

Homozygous mutations in four breast cancer predisposing genes (BRCA2, PALB2, BRIP1 and RAD51C) are involved in the FA pathway. Another gene involved in this pathway, the FANCM gene, is recently described in Finnish breast cancer families, who did not harbour BRCA1/2 mutations. ${ }^{[69]}$ FANCM mutation (p.Q1701X) was 3.5-fold more prevalent among Finnish TNBC patients as compared to the control population. This mutation was screened among 117 Pakistani TNBC patients, not harbouring $B R C A 1 / 2$ mutations. It was not detected, implying negligible or no contribution of this mutation to TNBC development in Pakistani population. ${ }^{\left[{ }^{70]} \text { However, }\right.}$ screening of FANCM exon 20 detected a missense mutation p.R1644Q in two unrelated early-onset TNBC patients with a frequency of $2.7 \%(2 / 75)$. It was predicted as deleterious by in silico analyses. The absence of this mutation among the control group of 188 healthy Pakistani women suggested that it may be a disease-causative. These findings warranted whole gene screening to better understand the contribution of the FANCM mutations to Pakistani TNBC women. ${ }^{[70]}$

\section{Low-penetrance Breast Cancer Loci and SNPs}

Breast cancer risk is also linked with several lowpenetrance breast cancer susceptibility loci and SNPs. BsmI 
(rs1544410), FokI (rs2228570) and Cdx-2 (rs11568820) variants in $V D R$ gene are among the frequently studied SNPs and are linked with breast cancer risk. ${ }^{[71-74]} V D R$ is mapped on chromosome 12 and encodes for $1 \alpha, 25$ dihydroxy Vitamin D3 receptor involved in regulation of calcium metabolism and maintenance of mammary gland. ${ }^{[75]}$ Decreased expression of VDR has been reported in breast tumours and is likely because of VDR gene polymorphisms. Conflicting results have been reported among Caucasian studies assessing the link of the two common SNPs (BsmI and FokI) with breast cancer risk. ${ }^{[72,73,76,77]}$ Insufficient data are available for Asian populations. ${ }^{[71,78]}$

To investigate the role of VDR BsmI and FokI SNPs in breast cancer development, a large case-control study was conducted in Pakistan comprising 463 early-onset or familial breast cancer cases (with known BRCA1/2 mutation status) and 1012 female controls. An increased breast cancer risk was associated with the B allele of the BsmI. Further analysis showed that this observation was limited to breast cancer patients who did not carry the $B R C A 1 / 2$ mutations. Moreover, this association was stronger in familial breast and/or ovarian cancer. No such associations for FokI were noted. ${ }^{[5]}$ This study showed that $V D R$ gene $B s m \mathrm{I}$ b allele is linked with an increased breast cancer risk in Pakistani women tested negative for $B R C A 1 / 2$. Another $V D R C d x-2$ polymorphism was also investigated in a small study comprising 264 premenopausal women from Southern Pakistan: 103 breast cancer cases and 161 unaffected individuals. No significant association of this SNP was noted with breast cancer risk. ${ }^{[79]}$

\section{Current Challenges and Future Perspectives}

The age-standardised incidence rate (ASR) of breast cancer in Pakistan (ASR $=50.3$ ) is lower than in North America (ASR = 92.9) and Europe (United Kingdom, $\mathrm{ASR}=95$, and Belgium, ASR = 111.9). ${ }^{[3]}$ However, the corresponding mortality rate in Pakistan (ASR $=25.2)$ is higher than in North America (ASR = 14.9) and Europe (United Kingdom, ASR $=17.1$, and Belgium, ASR $=20.3$ ). This may be due to distinct genetic spectrum and underlines the emerging concern of poorly defined healthcare facilities for the early diagnosis and treatment of breast cancer in Pakistan. Well-defined breast cancer studies and cancer screening policies may help to avoid such health disparities.
Breast cancer-associated syndromes also need to be considered to comprehend interlinking genetic factors. As an example, a novel pathogenic germline mutation was identified in the MSH2 gene of a Pakistani breast cancer patient, who did not carry mutations in $B R C A 1 / 2, C H E K 2$ and $R A D 51 C$ genes. This patient also reported a family history of malignancies within the spectrum of Lynch syndrome with a phenotypic overlap of HBOC. ${ }^{[80]}$ The optimisation of cancer risk management is challenging as overlapping cancer syndromes can add to the complexity of both genetic counselling and preventive strategies. Therefore, cancer geneticist needs to accompany oncologists to assess the appropriate susceptibility gene(s). This kind of service is only provided at the Shaukat Khanum Memorial Cancer Hospital and Research Centre (SKMCH and RC), to the breast/ovarian cancer families enrolled in genetic testing studies.

Studies conducted so far have shown a substantial contribution of BRCA1/2 germline mutations to breast cancer in Pakistani women. Further studies are warranted to analyse the prevalence of recurrent mutations in unselected breast cancer patients from this population. Despite extensive research, a large number of familial breast cancer cases are with unknown mutations. ${ }^{\left[{ }^{[1]}\right.}$ Technical advances such as next-generation sequencing facilities are now available to detect mutations in such cases. ${ }^{\left[{ }^{82}\right]}$ Using such technology for routine genetic testing requires critical consideration, in the context of mass screening in an economically challenged country like Pakistan.

\section{Conclusion}

About one in nine Pakistani women develops breast cancer during her lifetime. ${ }^{[83]}$ Since 2001, substantial research work is performed at SKMCH and $\mathrm{RC}$ to explore the prevalence and spectrum of major breast cancer susceptibility genes and SNPs in Pakistan. The knowledge obtained from these studies has enhanced our understanding about the contribution of major genes to Pakistani breast cancer. These findings will also be applicable to define appropriate strategies for the early diagnosis of breast cancer and also for better preventive and treatment. Comprehensive mutation analysis of the BRCA1/2, TP53, CHEK2, RAD51C, FANCM and VDR genes has been performed. All those samples revealing 
variants from these analyses were confirmed for the presence of mutations by DNA sequencing. In conclusion, the studies showed that mutations in $B R C A 1$ and $B R C A 2$ substantially contribute to HBOC in Pakistan. The studies provide evidence for other predisposing gene(s) contributing to breast and ovarian cancer development. However, TP53, CHEK2, RAD51C and FANCM mutations are less frequent in Pakistan. Overall, high-penetrance breast cancer susceptibility genes (BRCA1, BRCA2 and TP53) and moderate-penetrance genes (CHEK2, $R A D 51 C$ and $F A N C M$ ) account for $\sim 25 \%$ of breast cancer patients who were diagnosed at a young age or having a family history of breast/ovarian cancer. Knowledge of $B R C A 1 / 2$ mutation spectrum in a specific population has implications in risk-reducing strategies for highrisk breast cancer patients. ${ }^{[84]}$ Prophylactic bilateral mastectomy and/or oophorectomy reduce breast and ovarian cancer risk in women with $B R C A 1 / 2$ mutation. ${ }^{[85]}$ Offering extensive predictive genetic testing and genetic counselling to consanguineous families are also relevant in the Pakistani population. ${ }^{[35]}$ However, the facility of pre- and post-test genetic counselling in Pakistan is only provided at SKMCH and RC. Genetic testing for breast cancer predisposition in Pakistan may allow physicians to detect those women susceptible to breast and ovarian cancer and allow them to tailor preventive and therapeutic modalities based on their genotypes.

\section{Conflict of Interest}

The authors declare that they have no conflict of interest.

\section{References}

1. Sasco AJ. Breast cancer and the environment. Horm Res 2003;60 Suppl 3:50.

2. Ferlay J, Soerjomataram I, Dikshit R, et al. Cancer incidence and mortality worldwide: Sources, methods and major patterns in GLOBOCAN 2012. Int $\mathrm{J}$ Cancer 2015;136:E359-86.

3. Ferlay J, Soerjomataram I, Ervik M, et al. GLOBOCAN 2012. Available from: http://globocan.iarc.fr. [Last cited on 2018 Jan 20]

4. Aziz Z, Sana S, Saeed S, Akram M. Institution based tumor registry from Punjab: Five year data based analysis. J Pak Med Assoc 2003;53:350-3.

5. Rashid MU, Muzaffar M, Khan FA, et al. Association between the BSMI polymorphism in the vitamin D receptor gene and breast cancer risk: Results from a Pakistani casecontrol study. PLoS One 2015;10:e0141562.
6. Rebbeck TR. Inherited genetic predisposition in breast cancer. A population-based perspective. Cancer 1999;86:2493-501.

7. Apostolou P, Fostira F. Hereditary breast cancer: The era of new susceptibility genes. Biomed Res Int 2013;2013:747318.

8. Pasche B. Recent advances in breast cancer genetics. Cancer Treat Res 2008;141:1-0.

9. Pharoah PD, Antoniou A, Bobrow M, et al. Polygenic susceptibility to breast cancer and implications for prevention. Nat Genet 2002;31:33-6.

10. Hodgson SV, Morrison PJ, Irving M. Breast cancer genetics: Unsolved questions and open perspectives in an expanding clinical practice. Am J Med Genet C Semin Med Genet 2004;129C:56-64.

11. Hall JM, Lee MK, Newman B, et al. Linkage of earlyonset familial breast cancer to chromosome 17q21. Science 1990;250:1684-9.

12. Koonin EV, Altschul SF, Bork P. BRCA1 protein products. Functional motifs. Nat Genet 1996;13:266-8.

13. Miki Y, Swensen J, Shattuck-Eidens D, et al. A strong candidate for the breast and ovarian cancer susceptibility gene BRCA1. Science 1994;266:66-71.

14. Wooster R, Bignell G, Lancaster J, et al. Identification of the breast cancer susceptibility gene BRCA2. Nature 1995;378:789-92.

15. Wong AK, Pero R, Ormonde PA, et al. RAD51 interacts with the evolutionarily conserved BRC motifs in the human breast cancer susceptibility gene brca2. J Biol Chem 1997;272:31941-4.

16. Collins N, McManus R, Wooster R, et al. Consistent loss of the wild type allele in breast cancers from a family linked to the BRCA2 gene on chromosome 13q12-13. Oncogene 1995;10:1673-5.

17. Smith SA, Easton DF, Evans DG, et al. Allele losses in the region 17q12-21 in familial breast and ovarian cancer involve the wild-type chromosome. Nat Genet 1992;2:128-31.

18. Schlacher K, Christ N, Siaud N, et al. Double-strand break repair-independent role for BRCA2 in blocking stalled replication fork degradation by MRE11. Cell 2011;145:529-42.

19. Antoniou A, Pharoah PD, Narod S, et al. Average risks of breast and ovarian cancer associated with BRCA1 or BRCA2 mutations detected in case series unselected for family history: A combined analysis of 22 studies. Am J Hum Genet 2003;72:1117-30.

20. Chen S, Parmigiani G. Meta-analysis of BRCA1 and BRCA2 penetrance. J Clin Oncol 2007;25:1329-33.

21. Mavaddat N, Peock S, Frost D, et al. Cancer risks for BRCA1 and BRCA2 mutation carriers: Results from prospective analysis of EMBRACE. J Natl Cancer Inst 2013;105:812-22.

22. Tai YC, Domchek S, Parmigiani G, et al. Breast cancer risk among male BRCA1 and BRCA2 mutation carriers. J Natl Cancer Inst 2007;99:1811-4. 
23. Kim H, Choi DH. Distribution of BRCA1 and BRCA2 mutations in Asian patients with breast cancer. J Breast Cancer 2013;16:357-65.

24. Rashid MU, Zaidi A, Torres D, et al. Prevalence of BRCA1 and BRCA2 mutations in Pakistani breast and ovarian cancer patients. Int J Cancer 2006;119:2832-9.

25. Liede A, Malik IA, Aziz Z, et al. Contribution of BRCA1 and BRCA2 mutations to breast and ovarian cancer in Pakistan. Am J Hum Genet 2002;71:595-606.

26. Ahmad J, Le Calvez-Kelm F, Daud S, et al. Detection of BRCA1/2 mutations in breast cancer patients from Thailand and Pakistan. Clin Genet 2012;82:594-8.

27. Rashid MU, Muhammad N, Amin A, et al. Contribution of BRCA1 large genomic rearrangements to early-onset and familial breast/ovarian cancer in Pakistan. Breast Cancer Res Treat 2017;161:191-201.

28. Rashid MU, Muhammad N, Bajwa S, et al. High prevalence and predominance of BRCA1 Germline mutations in Pakistani triple-negative breast cancer patients. BMC Cancer 2016;16:673.

29. Rashid MU, Shah MA, Azhar R, et al. A deleterious BRCA1 mutation in a young Pakistani woman with metaplastic breast carcinoma. Pathol Res Pract 2011;207:583-6.

30. de la Hoya M, Fernández JM, Tosar A, et al. Association between BRCA1 mutations and ratio of female to male births in offspring of families with breast cancer, ovarian cancer, or both. JAMA 2003;290:929-31.

31. Rashid MU, Torres D, Zaidi A, et al. No association between BRCA mutations and sex ratio in offspring of Pakistani BRCA mutation carriers. Breast Cancer Res Treat 2008;107:155-6.

32. Rashid MU, Gull S, Faisal S, et al. Identification of the deleterious 2080insA BRCA1 mutation in a male renal cell carcinoma patient from a family with multiple cancer diagnoses from Pakistan. Fam Cancer 2011;10:709-12.

33. Gowen LC, Johnson BL, Latour AM, et al. Brcal deficiency results in early embryonic lethality characterized by neuroepithelial abnormalities. Nat Genet 1996;12:191-4.

34. Rashid MU, Torres D, Rasheed F, et al. No association of miscarriage and BRCA carrier status in Pakistani breast/ovarian cancer patients with a history of parental consanguinity. Breast Cancer Res Treat 2009;116:211-3.

35. Rashid MU, Muhammad N, Iqbal K, et al. BRCA1 genetic testing in a Pakistani breast-ovarian cancer family with multiple consanguineous marriages. Clin Genet 2015;88:198-9.

36. Okorokov AL, Sherman MB, Plisson C, et al. The structure of 553 tumour suppressor protein reveals the basis for its functional plasticity. EMBO J 2006;25:5191-200.

37. Harris CC. Structure and function of the p53 tumor suppressor gene: Clues for rational cancer therapeutic strategies. J Natl Cancer Inst 1996;88:1442-55.

38. Levine AJ. P53, the cellular gatekeeper for growth and division. Cell 1997;88:323-31.

39. Malkin D, Li FP, Strong LC, et al. Germ line p53 mutations in a familial syndrome of breast cancer, sarcomas, and other neoplasms. Science 1990;250:1233-8.

40. Chompret $\mathrm{A}$, Brugières L, Ronsin $\mathrm{M}$, et al. $\mathrm{P} 53$ germline mutations in childhood cancers and cancer risk for carrier individuals. Br J Cancer 2000;82:1932-7.

41. Buyru N, Tigli H, Dalay N. P53 codon 72 polymorphism in breast cancer. Oncol Rep 2003;10:711-4.

42. Aziz I, Rashid MU, Sultan F, et al. Frequency of pro allele on codon 72 of TP53 in female breast cancer patients of Pakistan: Molecular stress or geography. Pak J Zool 2013;45:1437-46.

43. Arcand SL, Maugard CM, Ghadirian P, et al. Germline TP53 mutations in BRCA1 and BRCA2 mutation-negative French Canadian breast cancer families. Breast Cancer Res Treat 2008;108:399-408.

44. Børresen AL, Andersen TI, Garber J, et al. Screening for germ line TP53 mutations in breast cancer patients. Cancer Res 1992;52:3234-6.

45. Lalloo F, Varley J, Ellis D, et al. Prediction of pathogenic mutations in patients with early-onset breast cancer by family history. Lancet 2003;361:1101-2.

46. Rashid MU, Gull S, Asghar K, et al. Prevalence of TP53 germ line mutations in young Pakistani breast cancer patients. Fam Cancer 2012;11:307-11.

47. Rashid MU, Muhammad N, Faisal S, et al. Constitutional CHEK2 mutations are infrequent in early-onset and familial breast/ovarian cancer patients from Pakistan. BMC Cancer 2013;13:312.

48. Rashid MU, Muhammad N, Faisal S, et al. Deleterious RAD51C Germline mutations rarely predispose to breast and ovarian cancer in Pakistan. Breast Cancer Res Treat 2014;145:775-84.

49. Bartek J, Lukas J. Chk1 and chk2 kinases in checkpoint control and cancer. Cancer Cell 2003;3:421-9.

50. Ahn J, Urist M, Prives C. The chk2 protein kinase. DNA Repair (Amst) 2004;3:1039-47.

51. Cybulski C, Górski B, Huzarski T, et al. CHEK2 is a multiorgan cancer susceptibility gene. Am J Hum Genet 2004;75:1131-5.

52. Nevanlinna H, Bartek J. The CHEK2 gene and inherited breast cancer susceptibility. Oncogene 2006;25:5912-9.

53. Cybulski C, Wokołorczyk D, Jakubowska A, et al. Risk of breast cancer in women with a CHEK2 mutation with and without a family history of breast cancer. J Clin Oncol 2011;29:3747-52.

54. Lee AS, Ang P. CHEK2*1100delC screening of Asian women with a family history of breast cancer is unwarranted. J Clin Oncol 2008;26:2419.

55. Thirthagiri E, Cheong LS, Yip CH, et al. CHEK2*1100delC does not contribute to risk to breast cancer among Malay, Chinese and Indians in Malaysia. Fam Cancer 2009;8:355-8.

56. Hollestelle A, Wasielewski M, Martens JW, et al. Discovering moderate-risk breast cancer susceptibility genes. Curr Opin Genet Dev 2010;20:268-76.

57. Rashid MU, Jakubowska A, Justenhoven C, et al. German 
populations with infrequent CHEK2*1100delC and minor associations with early-onset and familial breast cancer. Eur J Cancer 2005;41:2896-903.

58. Choi DH, Cho DY, Lee MH, et al. The CHEK2 1100delC mutation is not present in Korean patients with breast cancer cases tested for BRCA1 and BRCA2 mutation. Breast Cancer Res Treat 2008;112:569-73.

59. Rajkumar T, Soumittra N, Nancy NK, et al. BRCA1, BRCA2 and CHEK2 (1100 del C) Germline mutations in hereditary breast and ovarian cancer families in South India. Asian Pac J Cancer Prev 2003;4:203-8.

60. Jalilvand M, Oloomi M, Najafipour R, et al. An association study between CHEK2 gene mutations and susceptibility to breast cancer. Comp Clin Path 2017;26:837-45.

61. Baloch AH, Daud S, Raheem N, et al. Missense mutations (p.H371Y, p.D438Y) in gene CHEK2 are associated with breast cancer risk in women of Balochistan origin. Mol Biol Rep 2014;41:1103-7.

62. Vaz F, Hanenberg H, Schuster B, et al. Mutation of the RAD51C gene in a Fanconi anemia-like disorder. Nat Genet 2010;42:406-9.

63. Meindl A, Hellebrand H, Wiek C, et al. Germline mutations in breast and ovarian cancer pedigrees establish RAD51C as a human cancer susceptibility gene. Nat Genet 2010;42:410-4.

64. Sopik V, Akbari MR, Narod SA. Genetic testing for RAD51C mutations: In the clinic and community. Clin Genet 2015;88:303-12.

65. Thompson ER, Boyle SE, Johnson J, et al. Analysis of RAD51C Germline mutations in high-risk breast and ovarian cancer families and ovarian cancer patients. Hum Mutat 2012;33:95-9.

66. Vuorela M, Pylkäs K, Hartikainen JM, et al. Further evidence for the contribution of the RAD51C gene in hereditary breast and ovarian cancer susceptibility. Breast Cancer Res Treat 2011;130:1003-10.

67. Pang Z, Yao L, Zhang J, et al. RAD51C Germline mutations in Chinese women with familial breast cancer. Breast Cancer Res Treat 2011;129:1019-20.

68. Sato K, Koyasu M, Nomura S, et al. Mutation status of RAD51C, PALB2 and BRIP1 in 100 Japanese familial breast cancer cases without BRCA1 and BRCA2 mutations. Cancer Sci 2017;108:2287-94.

69. Kiiski JI, Pelttari LM, Khan S, et al. Exome sequencing identifies FANCM as a susceptibility gene for triple-negative breast cancer. Proc Natl Acad Sci U S A 2014;111:15172-7.

70. Rashid MU, Muhammad N, Khan FA, et al. Absence of the FANCM c.5101C $>$ T mutation in BRCA1/2-negative triple-negative breast cancer patients from Pakistan. Breast Cancer Res Treat 2015;152:229-30.
71. Dorjgochoo T, Delahanty R, Lu W, et al. Common genetic variants in the Vitamin D pathway including genome-wide associated variants are not associated with breast cancer risk among Chinese women. Cancer Epidemiol Biomarkers Prev 2011;20:2313-6.

72. Gnagnarella P, Pasquali E, Serrano D, et al. Vitamin D receptor polymorphism fokI and cancer risk: A comprehensive metaanalysis. Carcinogenesis 2014;35:1913-9.

73. Raimondi S, Pasquali E, Gnagnarella $\mathrm{P}$, et al. BsmI polymorphism of vitamin $\mathrm{D}$ receptor gene and cancer risk: A comprehensive meta-analysis. Mutat Res 2014;769:17-34.

74. Yao S, Zirpoli G, Bovbjerg DH, et al. Variants in the vitamin $\mathrm{D}$ pathway, serum levels of vitamin $\mathrm{D}$, and estrogen receptor negative breast cancer among African-American women: A case-control study. Breast Cancer Res 2012;14:R58.

75. Bhattacharjee M, Wientroub S, Vonderhaar BK. Milk protein synthesis by mammary glands of Vitamin D-deficient mice. Endocrinology 1987;121:865-74.

76. Tang C, Chen $\mathrm{N}, \mathrm{Wu} \mathrm{M}$, et al. Fok1 polymorphism of vitamin $\mathrm{D}$ receptor gene contributes to breast cancer susceptibility: A meta-analysis. Breast Cancer Res Treat 2009;117:391-9.

77. Wang J, He Q, Shao YG, et al. Associations between vitamin $\mathrm{D}$ receptor polymorphisms and breast cancer risk. Tumour Biol 2013;34:3823-30.

78. Shahbazi S, Alavi S, Majidzadeh AK, et al. BsmI but not FokI polymorphism of VDR gene is contributed in breast cancer. Med Oncol 2013;30:393.

79. Iqbal Mu, Khan TA, Maqbool SA. Vitamin D receptor cdx2 polymorphism and premenopausal breast cancer risk in southern Pakistani patients. PLoS One 2015;10:e122657.

80. Rashid MU, Naeemi H, Muhammad N, et al. A novel deleterious c.2656G $>$ T MSH2 Germline mutation in a Pakistani family with a phenotypic overlap of hereditary breast and ovarian cancer and Lynch syndrome. Hered Cancer Clin Pract 2016;14:14.

81. Shiovitz S, Korde LA. Genetics of breast cancer: A topic in evolution. Ann Oncol 2015;26:1291-9.

82. Lohmann K, Klein C. Next generation sequencing and the future of genetic diagnosis. Neurotherapeutics 2014;11:699-707.

83. Sohail S, Alam SN. Breast cancer in Pakistan - awareness and early detection. J Coll Physicians Surg Pak 2007;17:711-2.

84. McInerney NM, Narod S, Metcalfe K, et al. Breast cancer genetics for plastic surgeons. Plast Reconstr Surg 2017;140:455-60.

85. Rebbeck TR, Friebel T, Lynch HT, et al. Bilateral prophylactic mastectomy reduces breast cancer risk in BRCA1 and BRCA2 mutation carriers: The PROSE study group. J Clin Oncol 2004;22:1055-62. 